\title{
Prediction of particle charging in a dilute pneumatic conveying system
}

$\operatorname{AUTHOR}(\mathrm{S})$ :

Bunchatheeravate, Poom; Curtis, Jennifer; Fujii, Yusuke; Matsusaka, Shuji

\section{CITATION:}

Bunchatheeravate, Poom ...[et al]. Prediction of particle charging in a dilute pneumatic conveying system. AlChE Journal 2013, 59(7): 23082316

\section{ISSUE DATE:}

2013-07

URL:

http://hdl.handle.net/2433/229113

\section{RIGHT:}

This is the accepted version of the following article: [Bunchatheeravate, P., Curtis, J., Fuiii, Y. and Matsusaka, S. (2013), Prediction of particle charging in a dilute pneumatic conveying system. AlChE J., 59: 2308-2316], which has been published in final form at https://doi.org/10.1002/aic. 14025. This article may be used for non-commercial purposes in accordance with Wiley Terms and Conditions for Self-Archiving.: The full-text file will be made open to the public on 17 June 2014 in accordance with publisher's 'Terms and Conditions for Self-Archiving': This is not the published version. Please cite only the published version.; この論文は出版社版でありません。引用の際には出版社版をご確認ご利用くだ 


\title{
Prediction of Particle Charging in a Dilute Pneumatic Conveying System
}

\author{
Poom Bunchatheeravate $^{\mathrm{a}}$, Jennifer Curtis ${ }^{\text {a }}$, Yusuke Fujii ${ }^{\mathrm{b}}$, Shuji Matsusaka ${ }^{\mathrm{b}}$ \\ aDept. of Chemical Engineering, University of Florida, Gainesville, FL 32611, USA \\ bept. of Chemical Engineering, Kyoto University, Kyoto 615-8510, Japan
}

\begin{abstract}
When particles are transported in pipelines, they acquire electrostatic charges as they come into contact with the pipe wall. Charged particles can cause problems such as particle agglomeration, blockage, and explosion. Understanding the particle charge can help to prevent these issues. This study investigates a technique for predicting the particle charge in a straight pipe of any given length, as well as the pipe length at which electrostatic equilibrium occurs, through experimentation in a short $1 \mathrm{~m}$ pipe section. Experimentation with five different types of particles and four pipe wall materials at longer pipe lengths were used to validate the technique. This predictive technique is applicable to a range of particle shapes and sizes under the restriction that charge transfer is due to impact charging.
\end{abstract}

Heading:

Particle technology and fluidization

Keywords:

Electrostatics, Tribocharging, Contact electrification, Pneumatic conveying 


\section{Introduction}

Particle charging is a common phenomenon that occurs naturally and frequently. Any process that uses dry powders will involve charged particles. Dilute-phase pneumatic conveying, in which particles are suspended in gas and transported in a pipeline, is a common process found in many particle processing and manufacturing industries ${ }^{1,2}$. As particles are being transported, they acquire electrostatic charge upon contact with the pipe wall. Among all the operating processes, the pneumatic conveying process generates the most charge on the particles ${ }^{3}$.

Many studies have shown that overly-charged particles during handling and transportation can lead to dust explosion ${ }^{5-7}$. In addition to explosion, charged particles can hinder the transport operation. The presence of charged particles in the pipeline can increase the pressure drop ${ }^{8}$, cause blockage ${ }^{9}$, and damage sensors ${ }^{6}$. In pharmaceutical applications, charged particles can agglomerate and segregate, leading to changes in drug formulation and dosages ${ }^{10,11}$. Charged particles generated in medical inhalers can led to drastically different deposition patterns in the lung ${ }^{12}$. On the other hand, particle charging can be beneficial; it is possible to use the measured particle charge to create an online, non-intrusive monitoring system for flow information, including but not limited to mass loading, particle distribution and solid velocity ${ }^{13-17}$.

Different methods have been used to study the effects of electrostatic charge, using both computer simulations and experimentation. Lim et al. ${ }^{18}$ used large eddy simulation and the discrete element method (DEM) to investigate the effects of electrostatic charge on 
flowing granular materials. They found that charged particles exhibit a ring-like distribution during pipe flow with more particles found closer toward the pipe wall. They also investigated the effect on the drag force and the electric field generated due to the electrostatic force. Watano et al. ${ }^{19}$ performed DEM simulations as well as experiments to investigate electrostatic charging when a pile of PMMA particles was blown through a horizontal pipe. They found that the number of wall collisions and the vertical component of the impact velocity are important parameters for charging.

However, most of the research on particle charging has been experimental, focused on determining the overall dependency of electrostatic charging on specific parameters. Masuda et al. $^{20}$ coated a section of a pipeline with a polymer film and used a galvanometer to measure the current transfer upon impact. The number of particle contacts with the wall was then related to the charge transfer. They found that the current transfer between particles and the pipe surface depends on the contact frequency, contact area, contact time, and particle size. Smeltzer et al. ${ }^{21}$ measured the charge buildup on glass beads flowing through plexi-glass pipes. Nickel wires were inserted into the plexiglass pipe, and the charge was measured when particles came into contact with the wire. They found that the charge was linearly related to the collision frequency, which was measured in the various pipe sections. They also determined that impact charging was the primary mechanism for charge transfer in dilute pneumatic conveying. Yao et al. ${ }^{22}$ used electrical capacitance tomography, together with particle imaging velocimetry, to measure the time required for a flowing particle system to reach electrostatic equilibrium in a cyclic pipe flow. They found that a longer time is required for a more complex 
geometry, and electrostatic equilibrium is reached faster in a horizontal pipe than a vertical pipe.

Rather than measuring the charge transfer between particles and pipe surfaces, it is also possible to directly measure the charge on particles using a Faraday cup, also known as a Faraday cage. In this method, when particles enter the Faraday cup, an electric current is sent to the electrometer. The current reading measured from the electrometer can then be directly related to the amount of charge possessed by the particles. Kanazawa et al. ${ }^{23}$ used an electrostatic voltmeter to measure the charge on the pipe surface and a Faraday cup to measure the particle charge in a flowing particle system. They found a bipolar distribution of charge for the irregularly shaped particles, but a single polar distribution of charge for spherical particles. Nieh and Nguyen $^{24}$ also used a Faraday cup to determine the effect of humidity, particle velocity, and particle diameter on particle charging behavior. They found that humidity has a significant effect on particle charging, and particles are neutralized at high humidity. Smaller particles were also found to have a higher charge to mass ratio.

Only a handful of previous studies have investigated the charging behavior for a single particle impact (impact charging) and how the charging can be controlled. Matsusaka et al. ${ }^{25}$ performed experiments using a $31 \mathrm{~mm}$ rubber sphere impacting on a steel plate and came to the conclusion that the charge transferred in a single impact depends on the initial charge of the material, the impact velocity and the contact area. Matsuyama and Yamamoto $^{26}$ performed experiments with $3 \mathrm{~mm}$ polymer particles and a metal plate; they 
found that the impact charge is linearly dependent on the initial charge of the particle. There is also a charge beyond which a particle will no longer gain or lose charge upon further impact; this is known as the equilibrium charge and is independent of the impact conditions. Watanabe et al. ${ }^{27}$ studied 500-600 $\mu \mathrm{m}$ drug particles impacting a stainless steel plate; they found that the equilibrium charge is related to the contact potential difference. Matsusaka et al. $^{28}$ also observed this equilibrium charging in a flowing particle system after a certain pipe length. Matsusaka et al. ${ }^{29}$ then confirmed in a flowing particle system that the amount of charge transfer is a function of the initial charge and the equilibrium charge. They observed that the amount of charge on the particles varies exponentially as a function of pipe length, and the charge transfer continues until particles reach equilibrium charge in the system. With this charging relationship, they were able to control the particle charge in pipe flow by changing the wall material with which the particles come in contact.

In an attempt to control particle charge, Matsusaka et al. have designed and built particle chargers $^{30,31}$. As particles flow through a conical or cylindrical chamber, the centrifugal force directs the particles toward the wall where they impact and become charged. The particle chargers work on the principle of contact electrification; a particle can gain or lose charge depending on the state of the material with which it comes in contact. The important parameters for the particle charger are the electrostatic properties between the particles and the wall surface and the applied electric field (see Appendix A for the effect of the electric field on the charge transfer). 


\section{Charge transfer model for metal-metal systems}

In metal-metal contact electrification, electrons are transferred between the surfaces. As a result, one material becomes positively charged while the other becomes negatively charged. The charge transfer $\Delta q_{M}$ between the two metals after one contact, without the influence of external electric field, is given by:

$$
\Delta q_{M}=C_{0} V_{c}
$$

where $C_{0}$ is the contact capacitance between the two metals and $V_{c}$ is the contact potential difference that is directly dependent on the work function of the two metals. The work function is related to the amount of energy that is required to strip electrons from the surface; this value is strongly influenced by the surface state (e.g., the amount of valance electrons on the surface). The contact potential difference between the two metals $V_{c}$ is given by

$$
V_{c}=-\frac{\left(\varphi_{a}-\varphi_{b}\right)}{e}
$$

where $\varphi$ is the work function for each metal, and $e$ is the elementary charge of an electron. Electrons move from the metal with the lower work function to the metal with the higher work function.

Contact electrification for two metals is fairly straightforward; however, when an insulator is involved, the theory becomes more complex. In addition to electron transfer 
in an insulator-insulator system, there are other possible mechanisms. These mechanisms involve the transfer of material ${ }^{32,33}$, ions $\mathrm{s}^{34,35}$, or radicals ${ }^{36,37}$. Irrespective of the transfer mechanism, the concepts in Eq. (2) can still be applied for an insulator-metal or insulatorinsulator systems. The work function of an insulator cannot be directly measured. The surface state (e.g. roughness, geometry, and surface chemistry), the environment (e.g. air or vacuum), and other physical conditions directly influence the work function of an insulator. For an insulator, an 'effective work function', measured at a specific condition, is used in place of the metal work function ${ }^{38}$.

\section{Charge transfer model for metal-insulator and insulator-insulator systems}

The typical charge transfer model that is applied for any two materials in contact is known as the condenser model $(\mathrm{CM})$. The condenser model describes the contact between the two materials in terms of a capacitor. The contact surfaces are considered to be the two plates in the capacitor, and the charge is transferred due to the potential difference of the two plates or materials. The complete details of this model can be found in Matsusaka et al. ${ }^{39}$. The total potential difference associated with the condenser model $\left(V_{C M}\right)$ when particles are in contact can be expressed as:

$$
V_{C M}=V_{c}-V_{e}-V_{b}+V_{e x}
$$

where $V_{C}$ is calculated from Eq. (2) and based on the effective work functions, $V_{e}$ and $V_{b}$ are the potential differences due to the image charge and the space charge, respectively, and $V_{e x}$ is the potential difference caused by external factors, e.g. an imposed electric 
field. ${ }^{31,39}$ Image charge occurs when the electric field from a point charge induces a charge on its surrounding. Space charge occurs when multiple point charges act together to form a cloud of charge. The terms $V_{e}$ and $V_{b}$ are both negative as both inhibit the charge transfer. The charge transfer in the condenser model can then be depicted as:

$$
\Delta q_{C M}=k_{c} C V_{C M}
$$

where $k_{c}$ is the charging efficiency and $C$ is the capacitance between the two materials. In the case of metal-metal contact, $k_{c}$ is equal to one, $C$ is equal to $C_{0}$, and $V_{e}=V_{b}=0$. In addition, if $V_{e x}=0$, then Eq. (4) reduces to Eq. (1) which describes the charge transfer for metal-metal contacts in the absence of an external electric field.

\section{Charge transfer model for repeated impacts}

To obtain the charge of a particle $q$ as a function of the number of contacts $n$ with a wall, a continuous quantity $\frac{d q_{C M}}{d n}$ is used:

$$
\frac{d q_{C M}}{d n}=k_{c} C V_{C M}(q)
$$

Eq. (5) is the continuous form of the single contact $(n=1)$ equation depicted in Eq. (4). During contact, $V_{e}$ and $V_{b}$ are proportional to $q$; they are generally defined as:

$$
V_{e}=k_{e} q
$$




$$
V_{b}=k_{b} q
$$

where $k_{e}$ and $k_{b}$ are constants associated with the effect of the image charge and space charge respectively. The terms $V_{C}$ and $V_{e x}$ are not a function of $q$, and are treated as constants.

In addition to these contributions to charge transfer, Itakura et al. ${ }^{40}$ found that electrostatic leakage from the particle electric field to its surroundings, after the particles are no longer in contact, plays a significant role in the final charge of the particle. This effect is directly proportional to $q$ i.e.

$$
\frac{d q_{r}}{d n}=-k_{r} q
$$

where $k_{r}$ is a constant associated with the effect of charge leakage. The total charge transfer $\frac{d q}{d n}$ can then be represented by

$$
\frac{d q}{d n}=\frac{d q_{C M}}{d n}+\frac{d q_{r}}{d n}=-a q+b
$$

where constant $a$ includes the effects of the image charge, space charge, and charge leakage, and $b$ includes the effects of the work functions and the external electric fields. Eq. (9) can be solved as a first-order, non-homogeneous differential equation with the initial conditions $n=0$ and $q=q_{0}$, resulting in 


$$
q=q_{0} \exp (-a n)+\frac{b}{a}\{1-\exp (-a n)\}
$$

Eq. (10) can be further generalized into the following form:

$$
q=q_{0} \exp \left(-\frac{n}{n_{0}}\right)+q_{\infty}\left\{1-\exp \left(-\frac{n}{n_{0}}\right)\right\}
$$

where $q_{0}$ is the initial charge of the particle, $q_{\infty}$ is the equilibrium charge of the particle when $n$ tends to infinity, and $n_{0}$ is a constant specific to the particle-wall system. When applying this model to particle flow in a pipe, it can be assumed that the frequency of the particle-wall impacts per unit pipe length is constant, and that the number of impacts $n$ is proportional to the pipe length $L$. This assumption is valid for dilute, fully-developed flow in a straight pipe. In fully-developed flow, the average flow properties are independent of the position along the direction of the flow; therefore, the collision frequency can be assumed constant. Therefore, Eq. (11) can be rewritten as

$$
q(L)=q_{0} \exp \left(-\frac{L}{L_{0}}\right)+q_{\infty}\left\{1-\exp \left(-\frac{L}{L_{0}}\right)\right\}
$$

$L_{0}$ in Eq. (12) is analogous to $n_{0}$; this term is known as the characteristic length. Finally, dividing Eq. (12) through by the particle mass and replacing $q$ in Eq. (12) by the chargeto-mass ratio $q_{m}$, i.e. the specific charge, yields the following equation which describes the particle charge as a function of pipe length: 


$$
q_{\mathrm{m}}(L)=q_{\mathrm{m}, 0} \exp \left(-\frac{L}{L_{0}}\right)+q_{\mathrm{m}, \infty}\left\{1-\exp \left(-\frac{L}{L_{0}}\right)\right\}
$$

\section{Materials and Methods}

\section{Experimental setup}

The experimental system is composed of four sections including a feeder, a particle charger, a pipe, and a Faraday cup-electrometer as shown in Figure 1. Figure 1a gives a detailed diagram of the feeder section, which consists of a vibratory feeder and a particle ejector. The vibratory feeder was made by placing a long stem funnel on top of a stainless steel plate, and piezo-electric vibrators were connected to the funnel and plate. The particle mass flow rate was controlled by the electric signal sent from a feeder controller (VST-01 Control system, IMP Co. Ltd.). The particle mass flow rate in all experiments is kept approximately at $0.5 \mathrm{mg} / \mathrm{s}$ to ensure dilute-phase flow. Particles leaving the feeder were drawn, by vacuum, into a particle ejector. The particle ejector consists of two sections - upstream where the particles enter and downstream where the particles mix with the air and exit. A nozzle opening was used to separate the two sections and functioned to direct the compressed air toward the exit; in doing so, the compressed air created suction in the upstream section. The gas flow rate was controlled using a pressure controller; during the experiment, the gas velocity was kept at $15 \mathrm{~m} / \mathrm{s}$. To prevent electrostatic disturbance, all components in the feeder section were grounded.

After leaving the ejector, particles were sent to the particle charger in order to modify the particle charge. The particle charger used was the same one developed in Matsusaka's group $^{30,31}$. A diagram of the particle charger with a conical chamber is shown in Figure 
1b. Particles enter from the top and exit from the bottom of the charger; the broken line illustrates the particle flow path in the particle charger. The conical shape allows for maximum particle-wall contact as the particles flow through the charger. Within the particle charger, there is a cone shaped electrode at the center. The inner wall of the charger, i.e. inner electrode, was designed in such a way that the cavity was $0.01 \mathrm{~m}$ wide. The outer wall of the charger, i.e. the outer electrode, was grounded during operation. Both electrodes were made using stainless steel. A high voltage source (Matsusada Precission Inc.) was connected to the inner electrode to generate an electric field between the inner and outer walls of the cavity. As particles come into contact with the outer electrode, the particles can gain or lose electrons as explained in Appendix A. The final charge of the particles leaving the charger directly depends upon the charge supplied to the inner electrode.

Upon exiting the particle charger (or pipe), the particle charge was measured using a Faraday cup-electrometer. As shown in Figure 1c, the Faraday cup was connected to a vacuum system in order to collect particles into a thimble filter. The charge reading from the inner conductive surface was sent to the electrometer (Takeda Riken Co. Ltd.). The mass of the particles collected was determined using an analytical balance. The specific charge was obtained from the total charge and mass information. In each experiment, the mass of particles collected on the filter was used, along with experiment duration, to determine the average particle mass flow rate. The experiments were performed in ambient conditions with the relative humidity ranged from $30-50 \%$, and the temperature ranged from $20-23{ }^{\circ} \mathrm{C}$. To minimize the effect of humidity in the experiment, the 
compressed air was sent through a dryer that kept the relative humidity constant at $10 \%$ and the particles were kept in a desiccator until used for the experiments.

\section{Short Pipe Experimentation with Varying Initial Charge}

The schematics of the setups for these sets of experiments are shown in Figures $2 \mathrm{a}$ and $2 \mathrm{~b}$. The arrows on the left in Figure 2 represent particles exiting the particle ejector shown in Figure 1a. In Figures $2 \mathrm{a}$ and $2 \mathrm{~b}$, a polyurethane tube $(\mathrm{ID}=0.007 \mathrm{~m} ; L=0.3 \mathrm{~m})$ connects the particle ejector to the particle charger. A glass tube (ID $=0.007 \mathrm{~m} ; L=0.07 \mathrm{~m}$ ) was also used to direct the charged particles out of the particle charger. The Faraday cup was placed at the exit of the glass tube to measure $q_{m, 0}$, as seen in Figure 2a. The Faraday cup was also placed after the $1 \mathrm{~m}$ pipe to measure $q_{m}(L=1)$, seen in Figure $2 \mathrm{~b}$. Exit charge data $\left(q_{m}(L=1)\right)$ for the particles were collected for each particle-pipe material combination by varying the initial charge applied to the particles using the particle charger.

\section{Validation Experiments with Longer Pipes}

In order to validate the proposed technique, the exit charge data for the particles were collected at different lengths of pipe. The experimental setups are shown in Figure $2 \mathrm{c}$ and 2d. In these setups, a brass pipe (ID $=0.007 \mathrm{~m} ; L=0.1 \mathrm{~m}$ ) is placed after the particle ejector. The Faraday cup was positioned as seen in Figure $2 \mathrm{c}$ to measure $q_{m, 0}$ for these validation experiments. The setup in Figure $2 \mathrm{~d}$ was employed to collect particle charging data after 1-, 2-, 3-, and 4-m pipe length. The air flow rate in the pipes was measured 
after the ejector and after 1-, 2-, 3-, and 4-m pipe to ensure that there were no changes in the flow rate with each additional pipe length.

\section{Materials}

A total of five different types of particles and four different types of pipe wall materials were tested. A summary of particles and pipes with their specifications are found in Tables 1 and 2 respectively. The pipes were grounded during experiment.

\section{Results and Discussion}

\section{Varying Initial Charge in the Particle Charger}

The initial charge of the particles entering the $1 \mathrm{~m}$ pipe was adjusted using the particle charger (Figure 2a). The initial charge was measured at different voltages applied to the inner electrode of the charger. Figure 3 shows the specific charge of the borosilicate particles as a function of electric field strength in the particle charger. The polarity of the particle charge could be changed from negative to positive. However, there is a limit to the particle charging with higher applied electric field because of electrical discharge in the particle charger. Applying voltage higher than this limit causes a decrease in particle charge; this is demonstrated by the maximum in the curve shown in Figure 3. Other particles also show this decrease in particle charge. This is likely caused by the electrostatic air-breakdown, reducing the effect of the electric field in the charger.

\section{Short Pipe Experimentation with Varying Initial Charge}


Particle charge measurements were made using the setup in Figures $2 \mathrm{a}$ and $2 \mathrm{~b}$. The initial charge of the particles is denoted $q_{m, 0}$, and the particle charge collected after flowing in the $1 \mathrm{~m}$ pipe is denoted $q_{m}(L=1)$. The particle charge measurements were repeated three times. A relationship between $q_{m, 0}$ and $q_{m}(L=1)$ for borosilicate particles in the natural glass pipe is shown in Figure 4. In the figure, the data points represent the averages and the error bars represent the standard deviations for the measurements. The $q_{m}(L=1)$ versus $q_{m, 0}$ curve exhibits a linear relationship, which agrees with Eq. (9) in the theory on the repeated impacts model. Matsuyama and Yamamoto ${ }^{26}$ observed similar behavior in their single particle impact experiments. Figure 4 also includes a broken line representing $q_{m}(L=1)=q_{m, 0}$. The experimental data for $q_{m}(L=1)$ versus $q_{m, 0}$ are higher than the broken line; this result indicates that the particles obtained a positive charge from the wall by contact electrification. In other words, the electrons on the particles were transferred to the wall.

Figure 5 shows the experimental results of $q_{m}(L=1)$ versus $q_{m, 0}$ for borosilicate particles in a copper pipe. The $q_{m}(L=1)$ versus $q_{m, 0}$ curve again exhibits a linear relationship. However, in this case, the experimental line intersects with a line representing $q_{m, 0}=q_{m}(L=1)$ at a $q_{m, 0}$. The data points, with initial charge more negative than the intersection point, charged positively after conveying through a $1-\mathrm{m}$ pipe; while data points with more positive initial charge than the intersection point charged negatively in the pipe. This observation indicates that the particle charge will approach the intersection point as particles flow along the pipeline; this intersection point is the equilibrium charge. The equilibrium charge in Figure 5 is $-59 \mu \mathrm{C} / \mathrm{kg}$. If 
borosilicate particles flow through an infinitely long copper pipe, the particles will consistently reach this equilibrium charge value. An intersection point also exists for borosilicate particles-natural glass pipe system (Figure 4), but at a charge outside of the range presented in Figure 4. Due to the extensive amount of data, only the results of borosilicate particles flowing in a natural glass pipe and in a copper pipe are discussed as a representative example.

\section{Predicting particle charging using stair-stepping procedure}

A technique to predict particle charge in any given length of pipe is proposed in Figure 6. The solid curve, i.e. $q_{m}(L=1)$ versus $q_{m, 0}$ line, is the same as that in Figure 4 , which is the result for the borosilicate particles traveling through the natural glass pipe. First, an initial charge on the $q_{m, 0}=q_{m}(L=1)$ line is found. This point is labeled as $P_{0}$. From this point a vertical line to the $q_{m}(L=1)$ versus $q_{m, 0}$ line is drawn. This vertical line represents the final charge on the particles after traveling through $1 \mathrm{~m}$ of the natural glass pipe with initial charge $P_{0}$. A horizontal line is then drawn to the $q_{m, 0}=q_{m}(L=1)$ line in order to set a new initial charge $P_{1}$. If this stair-stepping process is repeated, the final charge of the particles at any given pipe length can be determined.

The $q_{m}(L=1)$ versus $q_{m, 0}$ line is not parallel to the $q_{m, 0}=q_{m}(L=1)$ line; therefore, at a certain point the two lines will intersect. This intersection point represents the value of the particle charge when it has reached its equilibrium state, i.e. the particles will no longer gain or lose charge, regardless of continued interactions with the pipe surface. 


\section{Predicting particle charging using the semi-theoretical equation}

The experimental measurements in the short $1 \mathrm{~m}$ pipe can be used to determine the two constants $q_{m, \infty}$ and $L_{0}$ in the semi-theoretical Eq. (13), which describes the particle charge as a function of pipe length. Those two parameters $q_{m, \infty}$ and $L_{0}$ are easily found using the relationship in Figure 4. In Figure 4, the specific charge of particles traveling through a pipe can be expressed as the following linear equation:

$$
q_{m}(L=1)=c q_{\mathrm{m}, 0}+d
$$

where $c$ and $d$ are constants. The equilibrium charge $q_{m, \infty}$ can be calculated by finding the intersection point between Eq. (14) and line $q_{m, 0}=q_{m}(L=1)$. Mathematically, this equilibrium charge is given by

$$
q_{\mathrm{m}, \infty}=\frac{d}{1-c}
$$

To order to determine $L_{0}$, a comparison of Eq. (14) to Eq. (13) results in:

$$
c=\exp \left(-\frac{L}{L_{0}}\right)
$$

or

$$
L_{0}=-\frac{L}{\ln c}
$$


The constants $c, d, q_{m, \infty}, L_{0}$, and the coefficient of determination of Eq. (14) $\left(R^{2}\right)$ for each type of particle in each pipe wall material are summarized in Table 3 . The values of $L_{0}$ are $11.3 \mathrm{~m}$ and $3.9 \mathrm{~m}$ for the borosilicate-natural glass and the borosilicate-copper systems, respectively. In general, as the value of $L_{0}$ increases, the slower the charge transfer between the particles and the wall. Based on the values of $L_{0}$ in Table 3 , the insulator-metal system exhibits higher charge transfer than the insulator-insulator system.

Figure 7 shows the predicted charging profiles for borosilicate particles in a natural glass pipe (Figure 7a) and copper pipe (Figure 7b). The lines in Figure 7 represent the initial particle charge of $-300 \mu \mathrm{C} / \mathrm{kg}, 0 \mu \mathrm{C} / \mathrm{kg}$, and $300 \mu \mathrm{C} / \mathrm{kg}$. Each line in Figure 7 was determined using Eq. (13) with $q_{m, \infty}$ and $L_{0}$ based on the short pipe experimentation; the stair-step procedure also yielded similar results. In Figure 7b, two of the initial charges were greater than the equilibrium charge, while one of the initial charges was less. The charge on the particles always approaches the equilibrium charge with additional pipe length. This explains the increase and decrease in charge in Figure $7 \mathrm{~b}$. In Figure 7, the particle charge approaches the equilibrium value more quickly (i.e. shorter pipe lengths) for the borosilicate-copper pipe (insulator-metal) system than for the borosilicate-glass (insulator-insulator) pipe system.. The charging profiles are symmetrical with respect to the equilibrium for the same absolute value of $q_{m, 0}-q_{m, \infty}$.

\section{Validating the technique}


To validate the technique for predicting particle charging in any given pipe length, particle charging data were collected using different lengths of pipe as shown Figures 2c and $2 \mathrm{~d}$. Again, the particle charge measurements were repeated three times. These data were compared with the predicted charging profiles as given by Eq. (13) with values for $q_{m, \infty}$ and $L_{0}$ based on the short pipe experimentation. For all the particle-pipe wall material combinations tested, the comparisons between predicted and measured charging profiles are in good agreement. Figure 8a compares the predicted charging profile to the experimental data for borosilicate particles flowing in the natural glass pipe. Figure $8 \mathrm{~b}$ shows the comparisons between predicted and measured charging profiles for borosilicate particles in the copper pipe. Two additional representative comparisons are shown in Figures $8 \mathrm{c}$ and $8 \mathrm{~d}$. Figure 8c presents the comparisons for PMMA spherical particles in a stainless steel pipe, and Figure 8d for non-spherical crushed soda lime glass particles in a Pyrex pipe. The small deviations are likely caused by variations in the surface state of pipes. Figures 8 shows that it is possible to predict particle charge along any pipe length by using Eq. (13) and performing a small-scale (1-m) experiment to determine parameters associated with the particle and pipe wall materials.

\section{Conclusions}

A technique using a small-scale experiment has been developed for predicting particle charging behavior in pipes of any given length. This technique was tested for a range of particle characteristics and pipe wall materials. A small-scale experimentation looking at changes in particle charge in a 1-m pipe was used to determine two parameters associated with the particle and pipe wall materials. These parameters, along with a predictive 
model equation, are used to predict the particle charge along any length pipe, irrespective of the initial charge of the particle. The predictive technique is applicable to any metalmetal, metal-insulator and insulator-insulator particle-wall system with two limitations. First, particle charging must be via the impact charging mechanism. For example, this predictive technique would not be applicable to dense-phase pneumatic conveying where particles are in sustained contact with the wall. Second, the particle and pipe wall materials and the operating conditions (e.g. air and solids flow rate), in which the two parameters $\left(q_{m, \infty}\right.$ and $\left.L_{0}\right)$ are determined from the short pipe experimentation, must be the same as the case in which particle charging is being predicted in longer length pipes. Given these two limitations, this predictive technique should work well for a full range of particle characteristics (including initial charge) and pipe wall materials.

\section{Acknowledgements}

The authors would like to acknowledge the funding from NSF-PIRE, project number NSF OISE 0968313 and Grant-in-Aid for Scientific Research (B) (No. 23360341) from the Japan Society for the Promotion of Science

\section{Literature Cited}

1. Rhodes M. Particle technology (2nd edition). West Sussex: John Wiley \& Sons, Inc., 2008.

2. Henthorn KH, Hrenya CM. Particle cohesion. In: Lee S, Henthron KH. Particle technology and applications. Indiana: CRC Press, 2012:17-29. 
3. Jones TB. Electrostatic problems in powder technology. NEPTIS-3. November, 1994. Kyoto: Nishi Engr.

4. Cartwright P, Singh S, Bailey A, Rose L. Electrostatic charging characteristics of polyethylene powder during pneumatic conveying. IEEE T Ind Appl. 1985;1A21(2):541-546.

5. Glor M. Hazards due to electrostatic charging of powders. J Electrostat. $1985 ; 16: 175-191$

6. Klinzing GE. Electrostatic in pneumatic conveying. In: Yang WC. Handbook of fluidization and fluid-particle system. CRC Press. 2003.

7. Riedewald F. Afire in a secondary pharmaceutical powder transfer operation. Process Saf Prog. 2012.

8. Macus RD, Leung LS, Klinzing GE, Rizk F. Pneumatic conveying of solids: A theoretical and practical approach. London: Chapman and Hall, 1990.

9. Forward K, Lacks D, Sankaran R. Triboelectric charging of granular insulator mixtures due solely to particle-particle interactions. Ind Eng Chem Res. 2009;48:2309-2314.

10. Peart J, Kulphaisal P, Orban JC. Relevance of electrostatics in respiratory drug delivery. Business Briefing: Pharmagenerics. 2003;84-87.

11. Supuk E, Hassanpour A, Ahmadian H, Ghadiri M, Matsuyama T. Triboelectrification and associated segregation of pharmaceutical bulk powders. KONA Powder and Particle J. 2011;29:208-223.

12. Leong FW, Smith KA, Wang CH, Matsusaka S, Hua J. Electrostatic effect on inertial particle transport in bifurcated tubes. AIChE J. 2006;61:2262-2270. 
13. Matsusaka S, Masuda H. Simultaneous measurement of mass flow rate and charge-to-mass ratio of particles in gas-solids pipe flow. Chem Eng Sci. 2006;61:2254-2261.

14. Matsusaka S, Fukuda H, Sakura Y, Masuda H, Ghadiri M. Analysis of pulsating electric signals generated in gas-solids pipe flow. Chem Eng Sci. 2008;63:13531360.

15. Deng X, Chen D, Yang W. Study on electrodynamic sensor of multi-modality system for multiphase flow measurement. Rev Sci Instrum. 2011;82:124701.

16. Gajewski JB. Electrostatic, inductive ring probe bandwidth. Meas Sci Technol. 1996;7:1766-1775.

17. Gajewski JB. Non-contact electrostatic flow probes for measuring the flow rate and charge in the two phase gas-solid flows. Chem Eng Sci. 2006;61:2262-2270.

18. Lim EWC, Yao J, Zhao Y. Pneumatic transport of granular material with electrostatic effects. AIChE J. 2012;58:1040-1059.

19. Watano S, Saito S, Suzuki T. Numerical simulation of electrostatic charge in powder pneumatic conveying process. Powder Technol. 2003;135-135:112-117.

20. Masuda H, Komatsu T, Iinoya, K. The static electrification of particles in gassolid pipe flow. AIChE J. 1972;22(3):558-564.

21. Smeltzer EE, Weaver ML, Klinzing GE. Individual electrostatic particle interaction in pneumatic transport. Powder Tech. 1982;33:31-42.

22. Yao J, Zhang Y, Wang $\mathrm{CH}$, Liang YC. On the electrostatic equilibrium of granular flow in pneumatic conveying systems. AIChE J. 2006;52(11):3775-3793. 
23. Kanazawa S, Ohkubo T, Nomoto Y, Adachi T. Electrification of a pipe wall during powder transport. $J$ Electrostat. 1995;35:47-54.

24. Nieh S, Nguyen T. Effects of humidity, conveying velocity, and particle size on electrostatic charges of glass bead in a gasous suspension flow. $J$ Electrostat. $1988 ; 21: 99-114$

25. Matsusaka S, Ghadiri M, Masuda, H. Electrification of an elastic sphere by repeated impacts on a metal plate. J Phys D: Appl Phys. 2000;33:2311-2319.

26. Matsuyama T, Yamamoto H. Characterizing the electrostatic charging of polymer particle by impact charging experiments. Adv Powder Technol. 1995;6(3):211220.

27. Watanabe H, Ghadiri M, Matsuyama T, Ding YL, Pitt KG, Maruyama H, Matsusaka S, Masuda M. Triboelectrification of pharmaceutical powders by particle impact. Int J Pharm. 2007;334:149-155.

28. Matsusaka S, Umemoto H, Nishitani M, Masuda H. Electrostatic charge distribution of particles in gas-solids pipe flow. J Electrostat. 2002;55:81-96.

29. Matsusaka S, Oki M, Masuda H. Control of electrostatic charge on particles by impact charging. Adv Powder Technol. 2007;19(2):229-244.

30. Matsusaka S, Ando K, Tanaka Y. Development of electrostatic charge controller for particles in gases using centrifugal contact. J Soc Powder Technol Jpn. 2008;45:380-386.

31. Matsusaka S. Control of particle tribocharging. KONA Powder and Particle J. 2011;29:27-38. 
32. Baytekin HT, Baytekin B, Incorvati JT, Grzybowski BA. Material transfer and polarity reversal in contact charging. Angew Chem Int Ed. 2012;51:4843-4847.

33. Lacks DJ. The unpredictability of electrostatic charging. Angew Chem Int Ed. 2012;51:6822-6823.

34. Diaz AF, Fenzel-Alexander D. An ion transfer model for contact charging. Langumuir. 1993;9:1009-1015

35. McCarty LS, Whitesides GM. Electrostatic charging due to separation od ion at interface: Contact electrification of ionic electrets. Angew Chem Int Ed. 2008;47:2188-2207.

36. Baytekin B, Baytekin HT, Grzybowski BA. What really drives chemical reactions on contact charged surfaces? J Am Chem Soc. 2012;134:7223-7226.

37. Sakaguchi M, Mikano M, Ohura T, Iwata T. Machanoanions produced by mechanical fracture of bacterial cellulose: Ionic nature of Glycosidic linkage and electrostatic charging. J Phys Chem A. 2012;116:9872-9877.

38. Castle G.Contact charging between insulators. J Electrostat. 1997;40-41:13-20.

39. Matsusaka S, Maruyama H, Matsuyama T, Ghadiri M. Triboelectric charging of powders: A review. Chem Eng Sci. 2010;65:5781-5807.

40. Itakura T, Masuda H, Ohtsuka C, Matsusaka S. The contact potential difference of powder and the tribo-charge. J Electrostat. 1996;38:213-226. 


\section{Appendix A. Effect of $V_{e x}$ on the contact potential}

The external electric field has a significant influence on contact electrification. The term $V_{e x}$ in Eq. (3) arises from the electric fields in the surrounding environment, including electric fields in nature (e.g. the earth magnetic field) and man-made electric fields (e.g. electric field from power line). A schematic of the electric potential of a particle in contact with a surface (Figure A.1) can help understand the effect of $V_{e x}$. In Figure A.1, the energy levels of the particle and wall are presented on the left and right hand sides, respectively. The Fermi level is a hypothetical energy level for an electron inside the particle. The vacuum level is the energy level such that the potential energy of the electron is zero. The difference between the Fermi level and the vacuum level is equal to the work function of the particle. Consider Case 1 in Figure A.1 where no external electric field is applied and the particle's work function $\left(\varphi_{a}\right)$ is higher than the wall's $\left(\varphi_{b}\right)$, while the potential difference due to image charge $\left(V_{e}\right)$ and space charge $\left(V_{b}\right)$ remain constant. The final voltage potential of the particle is determined by the work function and the final potential of the wall consists of the wall work function and the contribution from the image charge and the space charge. The charge transfer is equal to the potential difference of the two surfaces, $V$. During contact, electrons will transfer from lower voltage potential to higher voltage potential, as the potential is zero at the vacuum level. In Case 1, electrons will flow from the wall to the particle, resulting in negatively charged particles. Cases 2,3 , and 4 show what occurs when the external potential is applied to the wall surface. In Case 2, a small amount of potential is applied to the wall; the final potential of the wall is now closer to the potential of the particle. The result of such a contact is that smaller charge transfer occurs during contact, so that the 
resultant particle in Case 2 will not gain as many electrons as the resultant particle from Case 1. In Case 3, the potential of the wall is equal to the potential of the particle, and no charge transfer occurs between the particle and the wall. In Case 4, a strong electric field is applied to the wall such that the potential of the wall is higher than the work function of the particle. In this case, the vacuum level is shown for the wall as more energy is required to remove electrons from the surface of the wall than from the particle's surface. In Case 4, electrons transfer from the particle to the wall and particles becomes positively charged. The examples shown in Cases 2, 3, and 4 suggest that electric field can directly influence how particles are charged. The particle charger used in this study builds upon this concept. In the particle charger, the electric field is intentionally applied to the wall surface to artificially modify the potential difference between the particle and the wall. The charge of the impacted particle is directly related to the applied electric field. 
Table 1 Characteristics of particles used in the experiment

\begin{tabular}{lcccc}
\hline Material of particle & $\begin{array}{c}\text { Mass median } \\
\text { diameter } \\
(\mu \mathrm{m})\end{array}$ & $\begin{array}{c}\text { Mass mean } \\
\text { diameter }(\mu \mathrm{m})\end{array}$ & $\begin{array}{c}\text { Standard } \\
\text { deviation }(\mu \mathrm{m})\end{array}$ & Sphericity \\
\hline Borosilicate & 49 & 48 & 3 & 1 \\
Soda lime & 79 & 78 & 8 & 1 \\
PMMA & 67 & 67 & 16 & 1 \\
Crush soda lime & 66 & 66 & 16 & 0.75 \\
JSC-1A $(30-90 \mu \mathrm{m})$ & 55 & 54 & 16 & 0.86 \\
sieve fraction & & & & \\
\hline
\end{tabular}


Table 2 Characteristic of pipes used in the experiment

\begin{tabular}{lc}
\hline Material of pipe & Inner diameter $(\mathrm{m})$ \\
\hline Copper & 0.0070 \\
Stainless steel & 0.0070 \\
Natural glass & 0.0068 \\
Pyrex & 0.0068 \\
\hline
\end{tabular}


Table 3 Characteristic values for each particle in 1-m pipe

\begin{tabular}{|c|c|c|c|c|c|c|}
\hline $\begin{array}{l}\text { Material of } \\
\text { particle }\end{array}$ & $\begin{array}{l}\text { Material of } \\
\text { pipe }\end{array}$ & $R^{2}$ & $c(-)$ & $d(\mu \mathrm{C} / \mathrm{kg})$ & $L_{0}(\mathrm{~m})$ & $q_{\mathrm{m}, \infty}(\mu \mathrm{C} / \mathrm{kg})$ \\
\hline \multirow[t]{4}{*}{ Borosilicate } & Copper & 0.985 & 0.772 & -13.4 & 3.9 & -59 \\
\hline & Stainless steel & 0.976 & 0.256 & -83.8 & 0.7 & -113 \\
\hline & Natural glass & 0.982 & 0.915 & 60.2 & 11.3 & 711 \\
\hline & Pyrex & 0.995 & 0.949 & 24.1 & 19.1 & 473 \\
\hline \multirow[t]{4}{*}{ Soda lime } & Copper & 0.994 & 0.727 & -4.7 & 3.1 & -17 \\
\hline & Stainless steel & 0.985 & 0.241 & -42.3 & 0.7 & -56 \\
\hline & Natural glass & 0.994 & 0.908 & 19.5 & 10.3 & 212 \\
\hline & Pyrex & 0.994 & 0.916 & 14.7 & 11.4 & 175 \\
\hline \multirow[t]{4}{*}{ PMMA } & Copper & 0.896 & 0.556 & 339.8 & 1.7 & 766 \\
\hline & Stainless steel & 0.880 & 0.492 & 736.8 & 1.4 & 1451 \\
\hline & Natural glass & 0.963 & 0.594 & 204.8 & 1.9 & 504 \\
\hline & Pyrex & 0.991 & 0.697 & 111.4 & 2.8 & 368 \\
\hline \multirow[t]{4}{*}{ Crush soda lime } & Copper & 0.987 & 0.797 & 3.1 & 4.4 & 15 \\
\hline & Stainless steel & 0.996 & 0.588 & -2.5 & 1.9 & -6 \\
\hline & Natural glass & 0.990 & 0.911 & 15.9 & 10.7 & 179 \\
\hline & Pyrex & 0.993 & 0.956 & 12.5 & 22.2 & 285 \\
\hline \multirow{4}{*}{$\begin{array}{l}\text { JSC-1A } \\
(30-90 \mu \mathrm{m}) \\
\text { sieve fraction }\end{array}$} & Copper & 0.998 & 0.758 & -25.4 & 3.6 & -105 \\
\hline & Stainless steel & 0.997 & 0.390 & -27.3 & 1.1 & -45 \\
\hline & Natural glass & 0.997 & 0.884 & 30.8 & 8.1 & 265 \\
\hline & Pyrex & 0.998 & 0.951 & 10.3 & 19.9 & 211 \\
\hline
\end{tabular}


Figure 1. Diagram of a) particle feeder, b) particle charger, c) Faraday cup-electrometer. All units are in $\mathrm{mm}$.
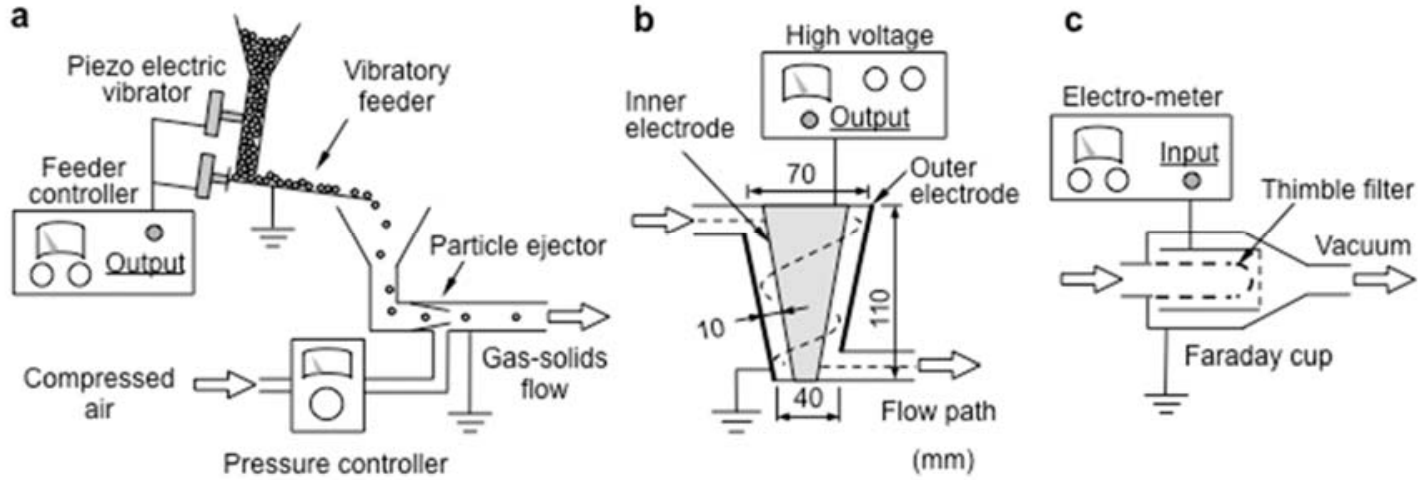
Figure 2. Experimental setup for determining a) initial particle charge after leaving the particle charger $b$ ) particle charge after $1-\mathrm{m}$ pipe length $\mathrm{c}$ ) particle charge leaving the ejector d) particle charge after different pipe lengths.

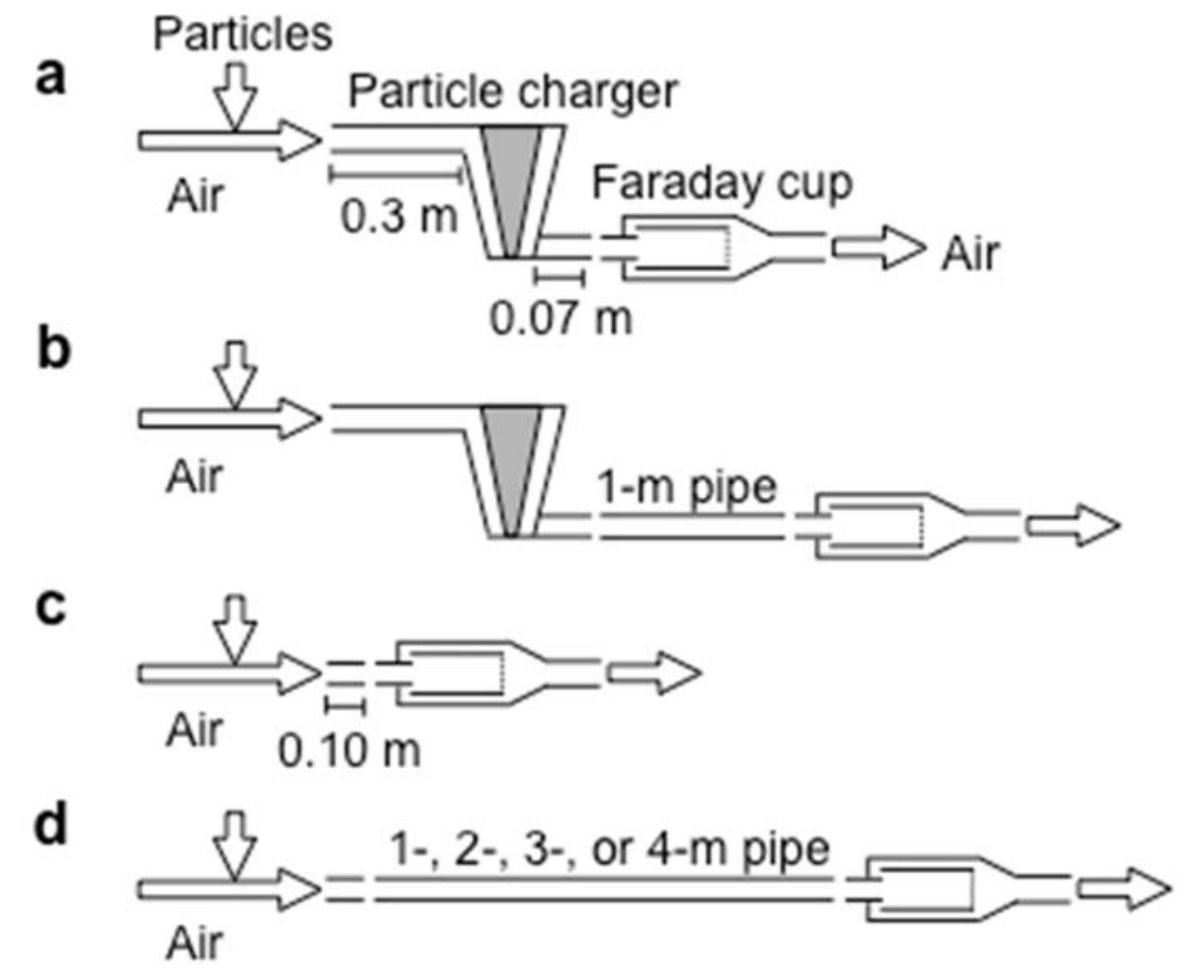


Figure 3. Specific charge of borosilicate particles leaving the particle charger as a function of applied electrical field in the particle charger.

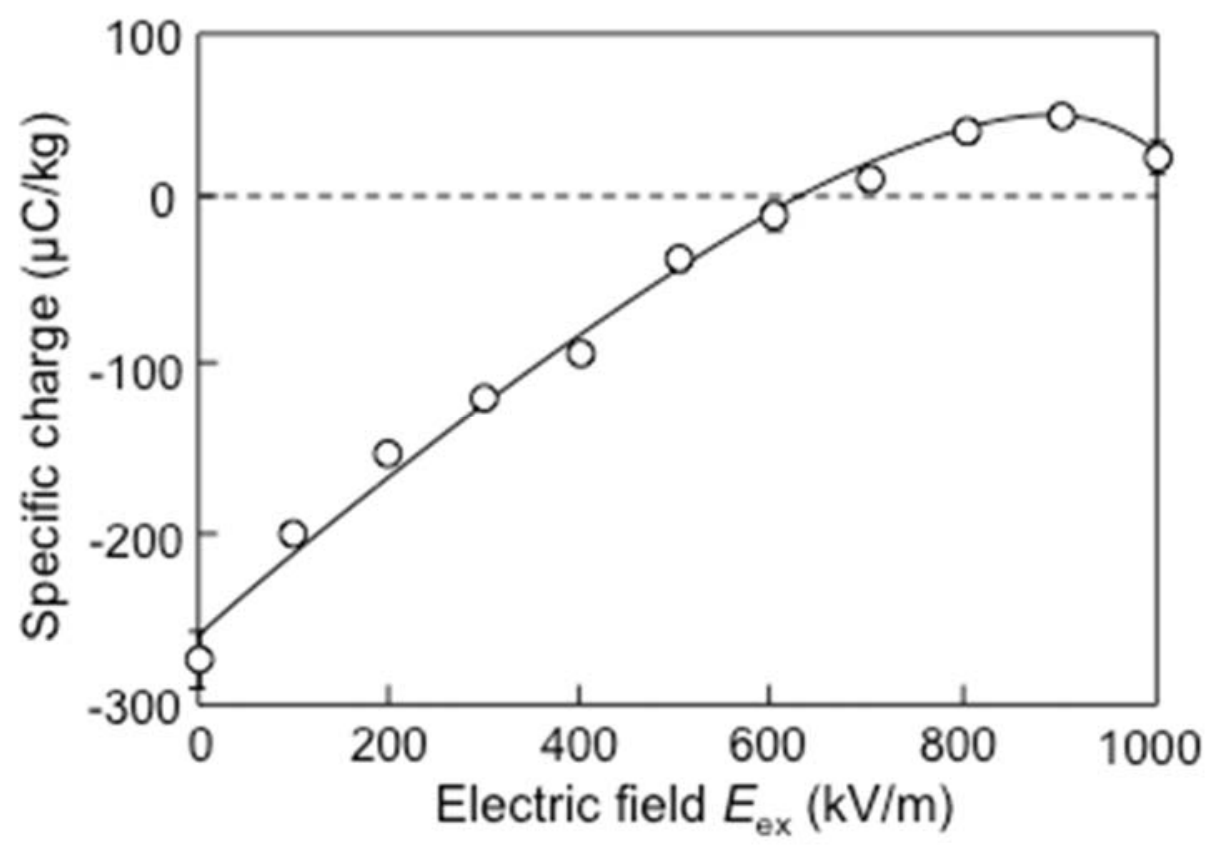


Figure 4. $q_{m}(L=1)$ vs. $q_{m, 0}$ for borosilicate particles in $1 \mathrm{~m}$ natural glass pipe

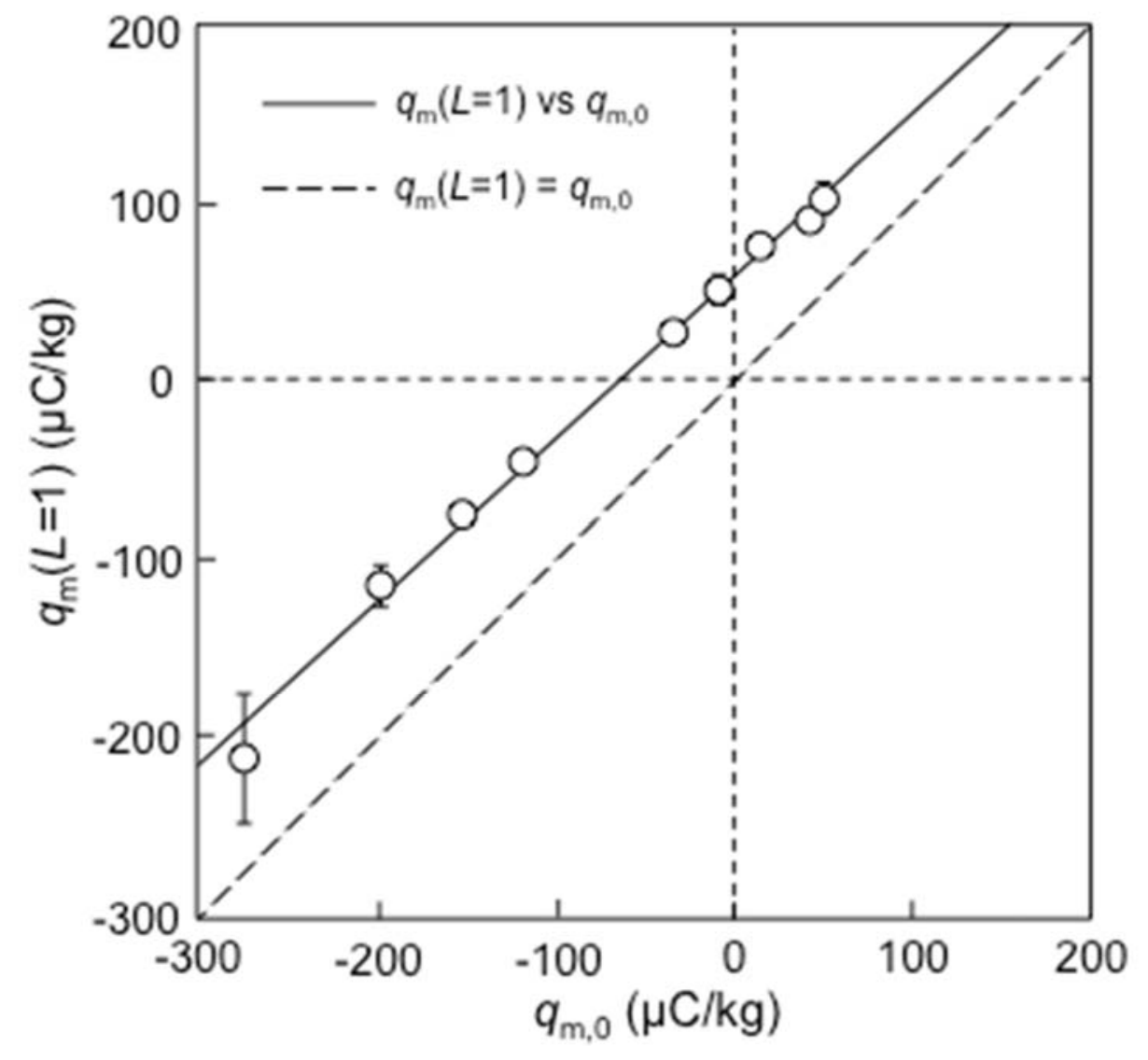


Figure 5. $q_{m}(L=1)$ vs. $q_{m, 0}$ for borosilicate particles in $1 \mathrm{~m}$ copper pipe

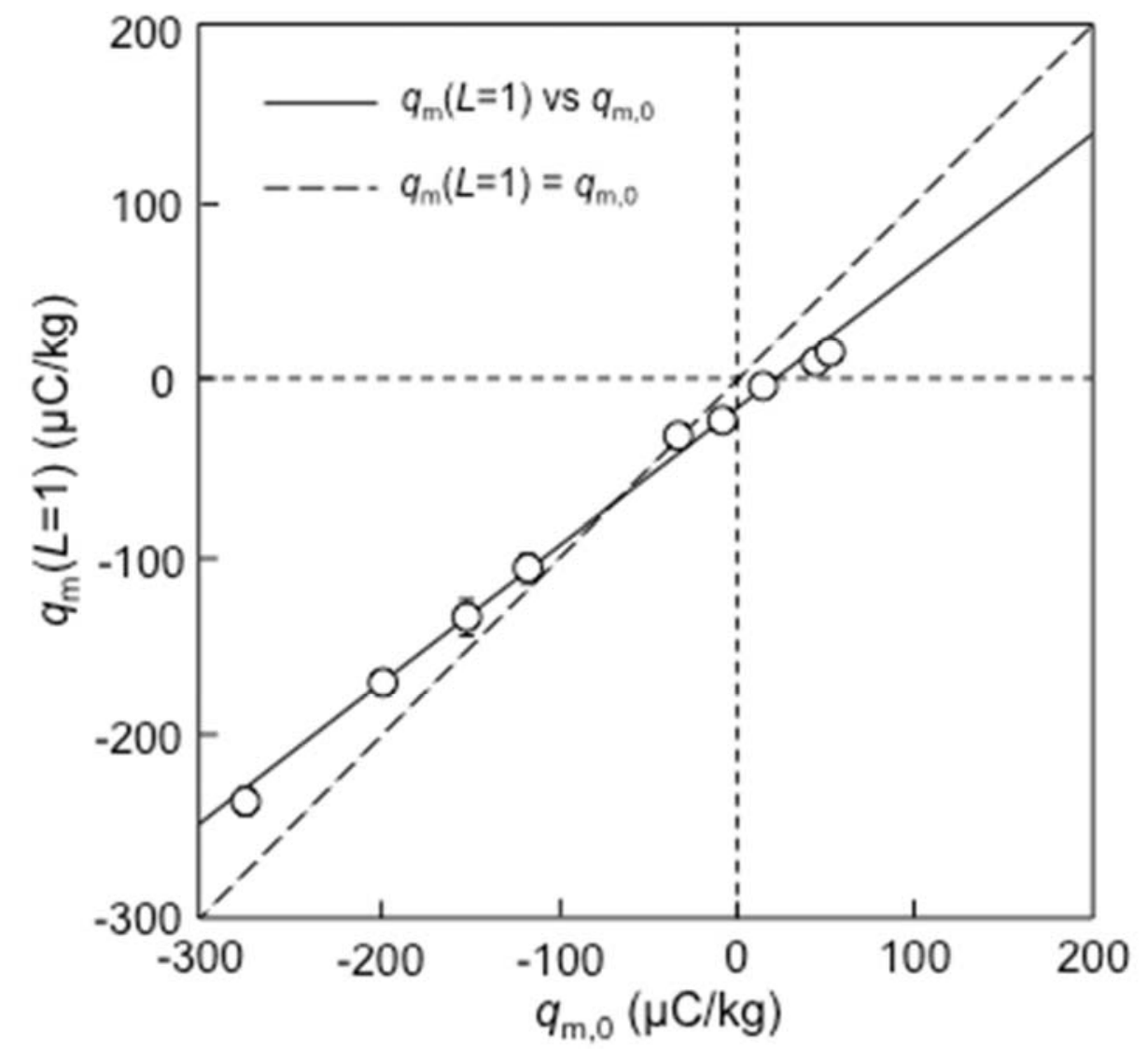


Figure 6. Predicting particle charge in natural glass pipe using stair-step method

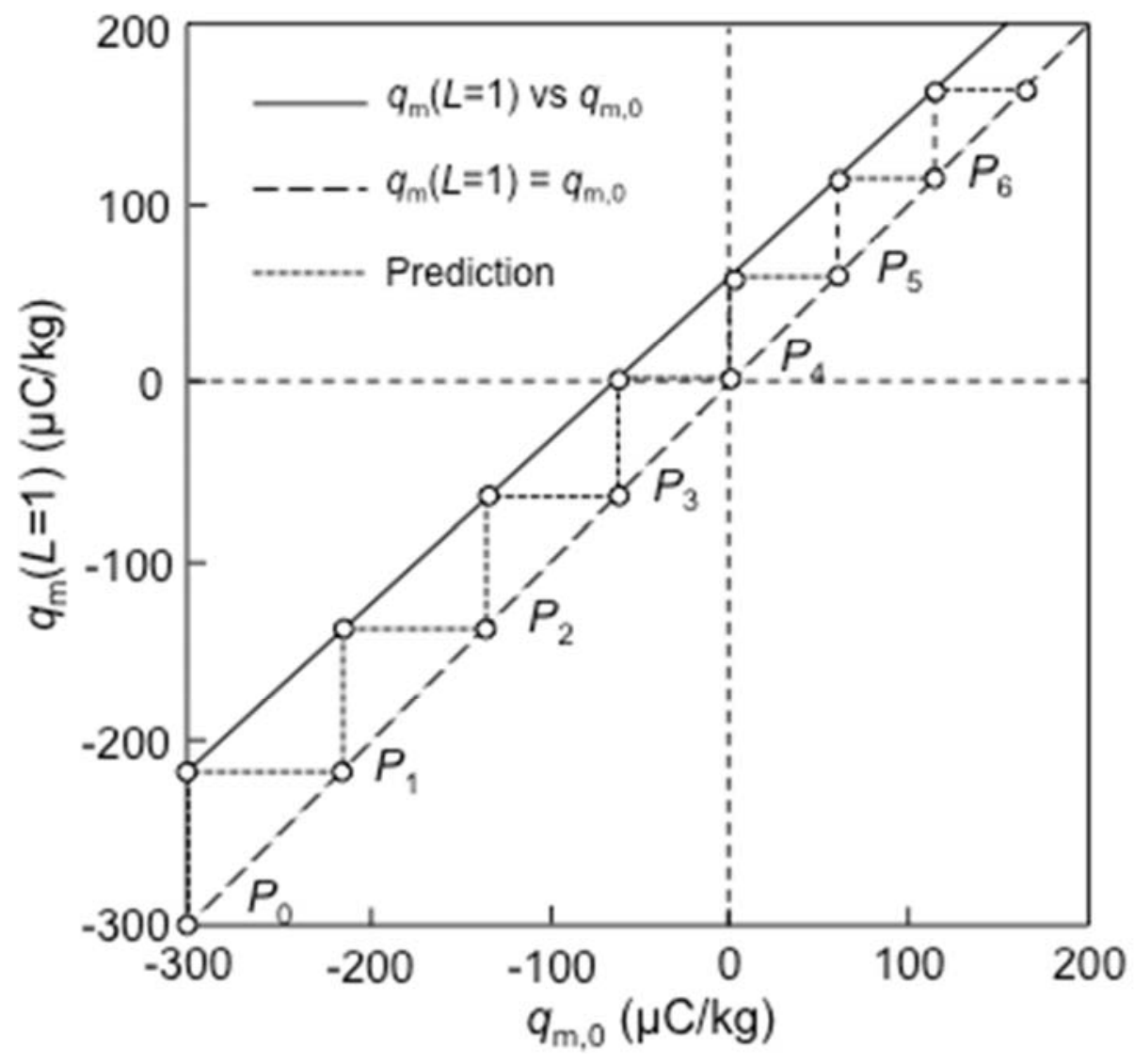


Figure 7. Predicting charging profile for borosilicate particles a) in natural glass pipe b) in copper pipe

a

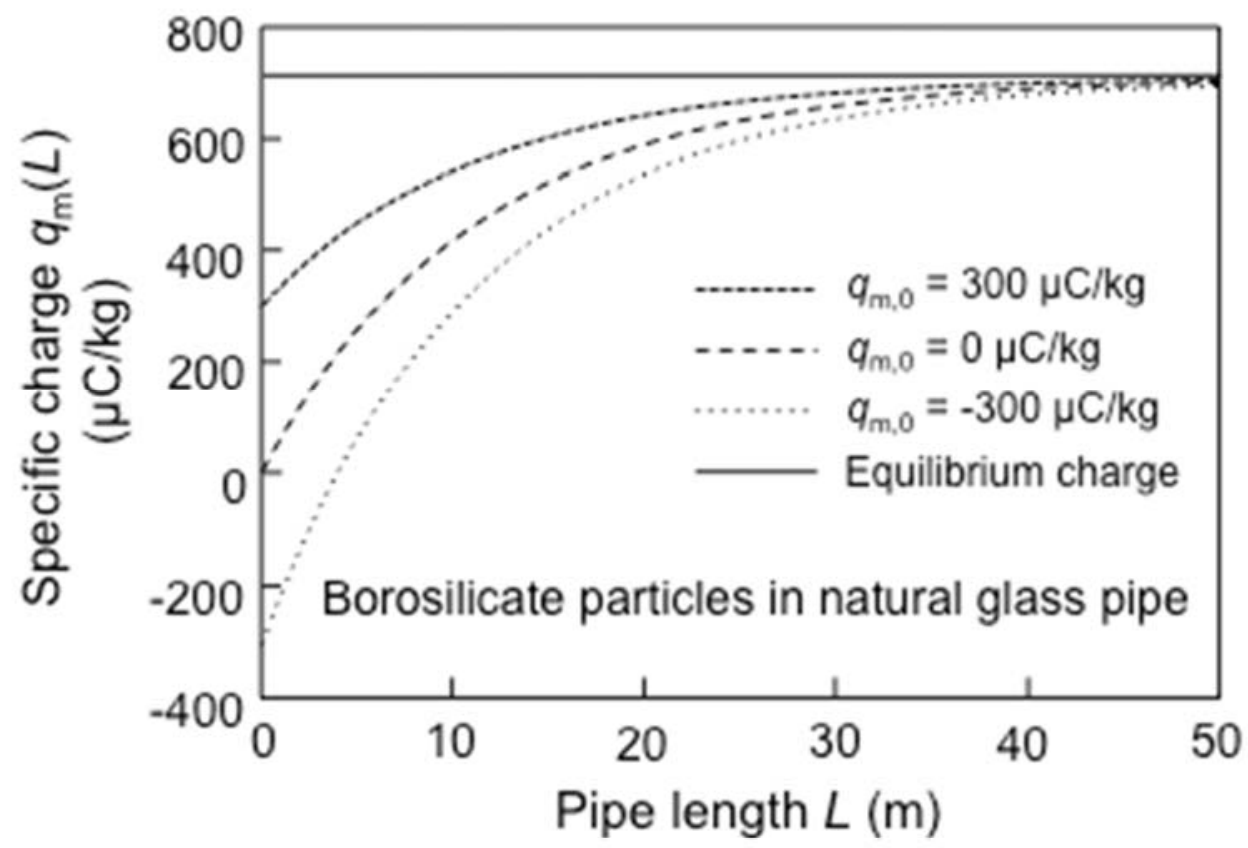

b

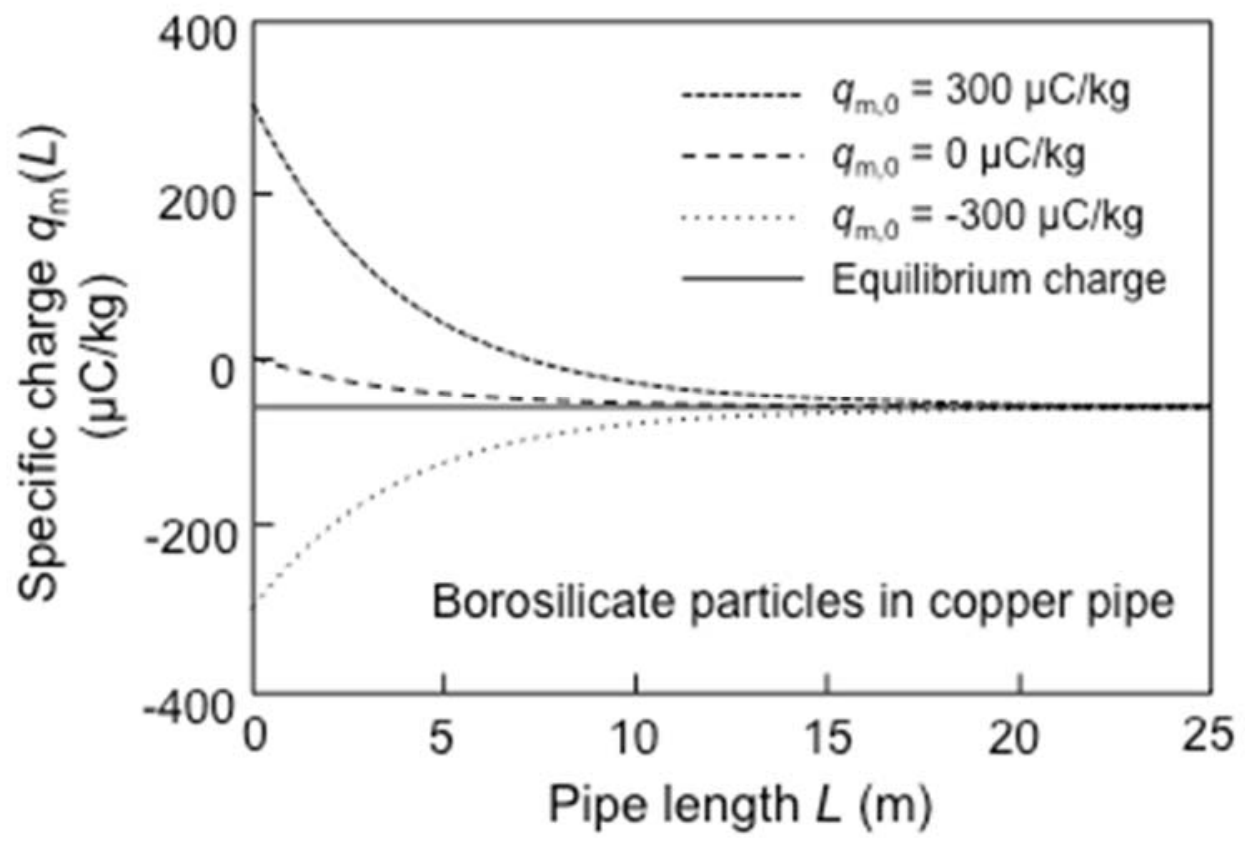


Figure 8. Comparison of the experimental data with predicted charging profile for a) borosilicate particles in natural glass pipe b) borosilicate particles in copper pipe c) PMMA particles in stainless steel pipe d) Crush soda lime particle in Pyrex pipe.

a

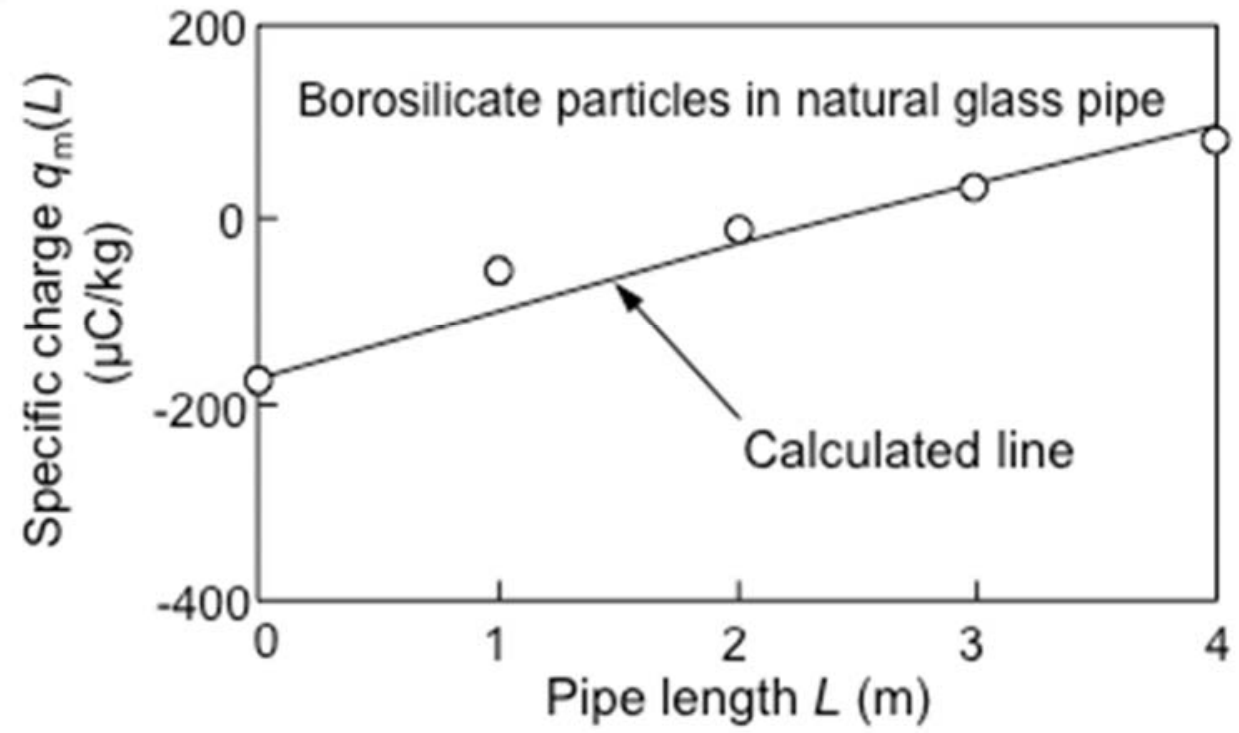

b

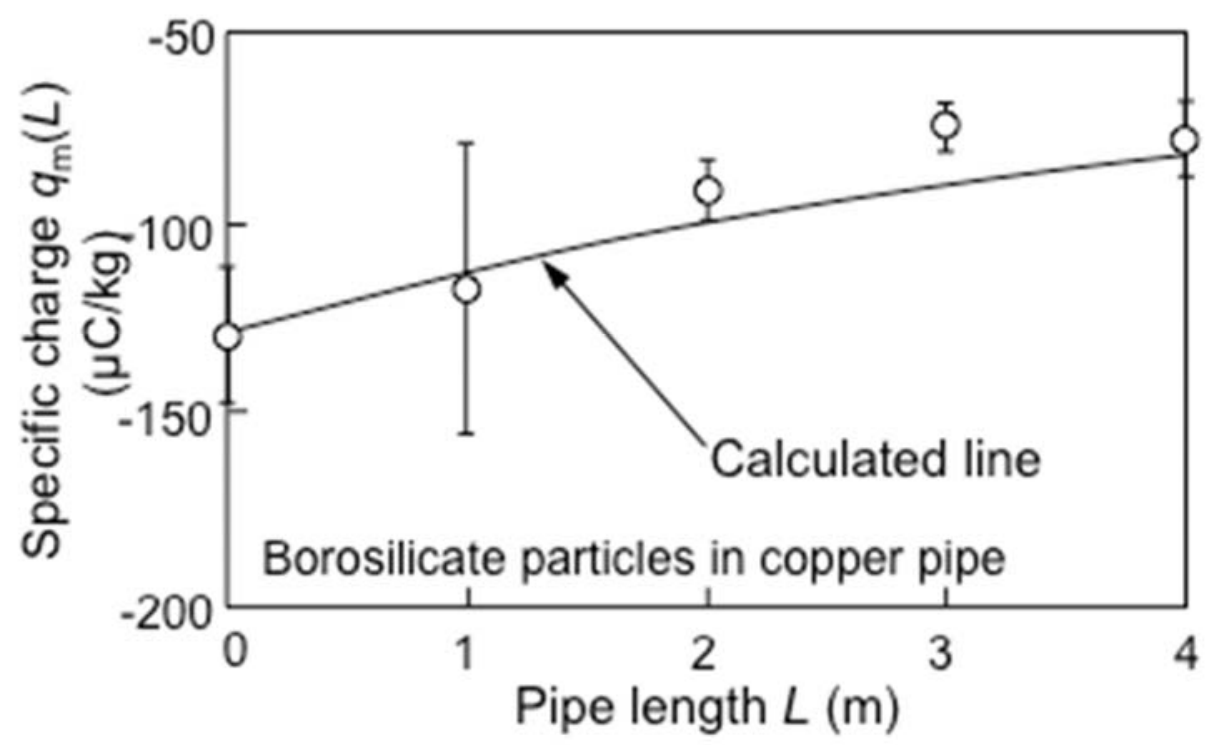


C

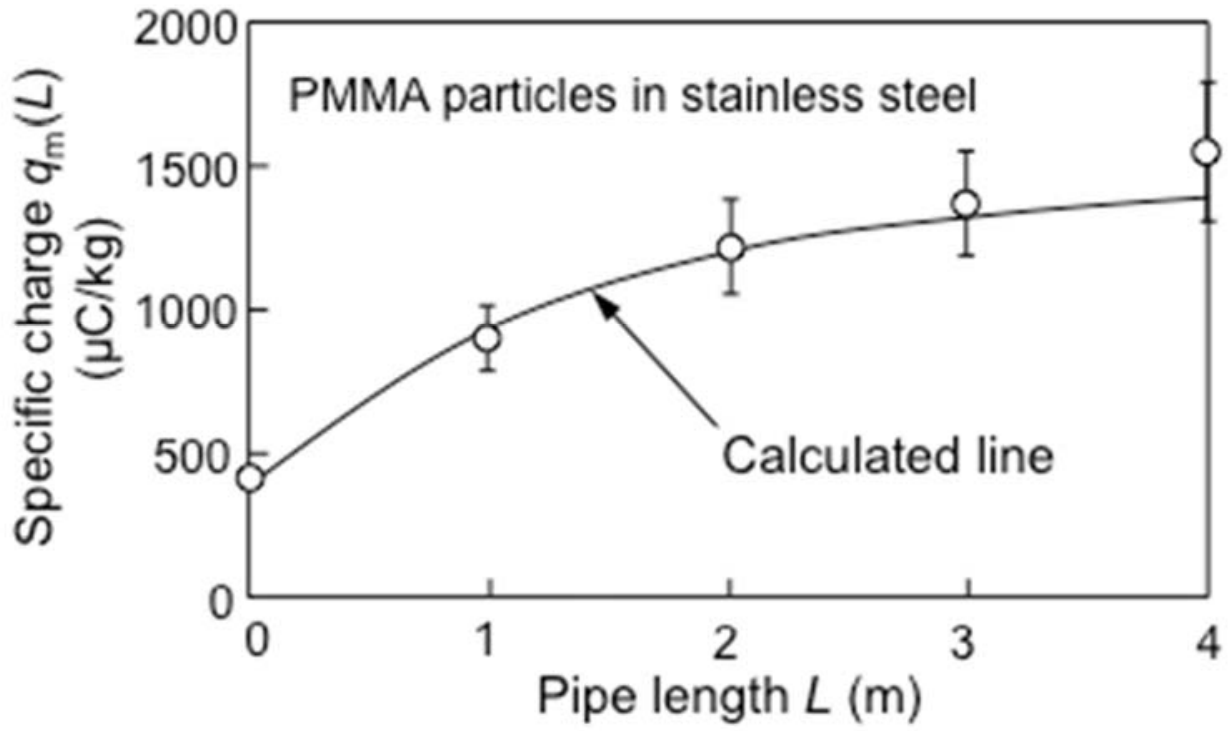

d

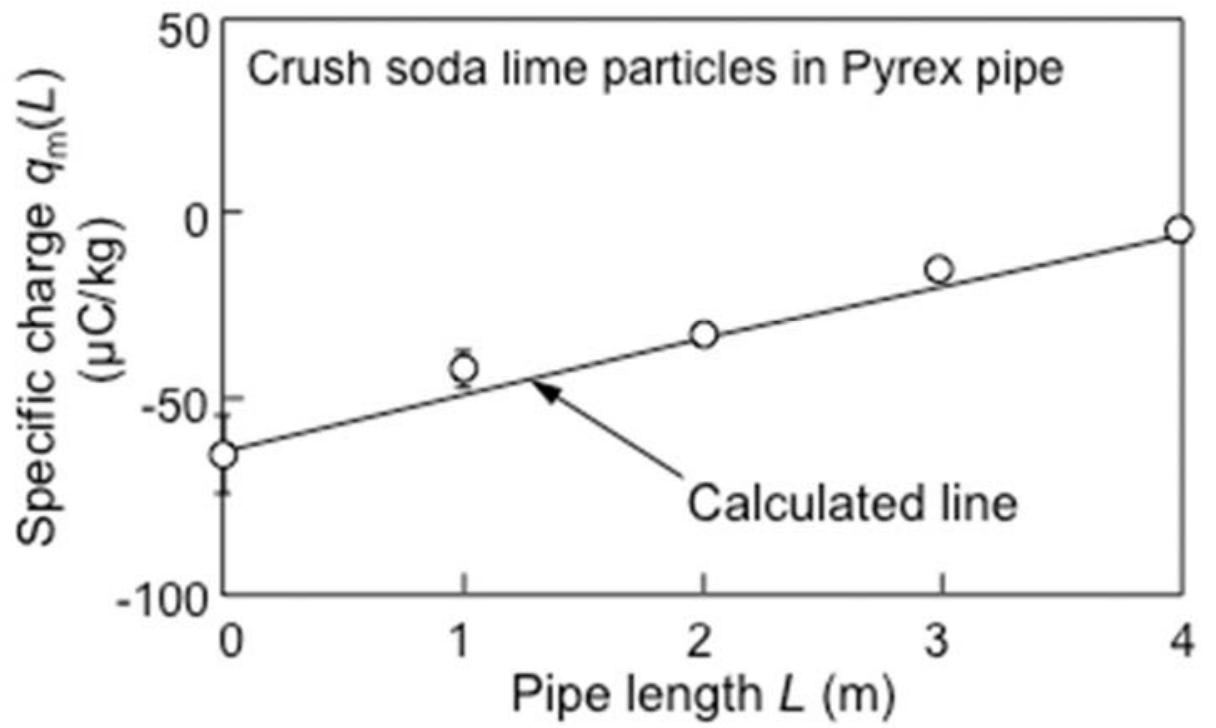


Figure A.1. Different cases of contact charge transfer in applied electric field.

$-\cdot \cdot \cdot-\cdot-$ Fermi level

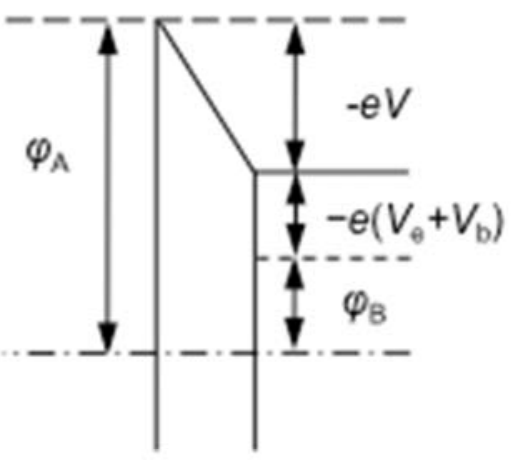

Particle Wall

$\varphi_{\mathrm{A}}>\varphi_{\mathrm{B}}+e\left(-V_{\mathrm{a}}-V_{\mathrm{b}}\right)$
$V<0$

Case 1

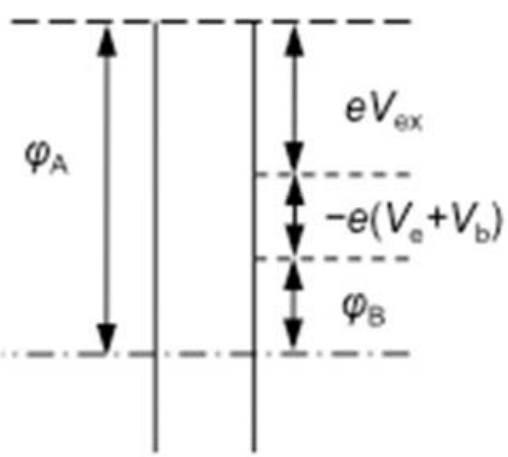

Particle Wall

$$
\begin{gathered}
\varphi_{A}=\varphi_{B}+e\left(V_{e x}-V_{\theta}-V_{b}\right) \\
V=0
\end{gathered}
$$

Case 3
----- Vacuum level

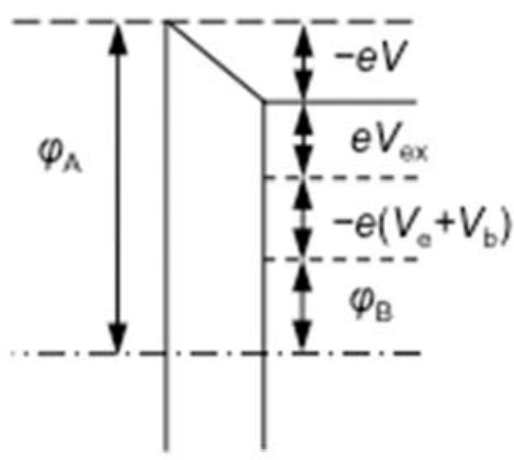

Particle Wall

$\varphi_{\mathrm{A}}>\varphi_{\mathrm{B}}+e\left(V_{\mathrm{ex}}-V_{\mathrm{e}}-V_{\mathrm{b}}\right)$
$V<0$

\section{Case 2}

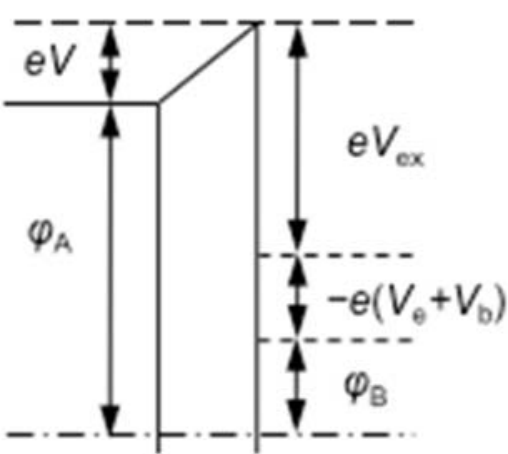

Particle Wall

$\varphi_{A}<\varphi_{B}+e\left(V_{e x}-V_{\theta}-V_{b}\right)$
$V>0$

Case 4 